\title{
English Language Teaching and the Promotion of Academic Ethics
}

\author{
Berrington Ntombela \\ (Caledonian College of Engineering, Sultanate of Oman) \\ doi:10.7575/aiac.alls.v.2n.2p.197
}

\begin{abstract}
Institutions of higher learning carry a burden of inculcating a culture of academic ethical behaviour among students as part of their responsibility to produce citizens of high calibre. In fact, this burden is more expedient and pronounced because of aberrant behaviours such as cheating that can potentially affect institutions' credibility. This paper therefore looks into the prevalent attitude towards cheating among students in a University College in Oman. The research is carried out qualitatively through video recording a testing session and through unstructured interviews in order to gather evidence of cheating and to establish reasons why students cheat. Most importantly, it seeks to address this attitude by advocating the role that English Language Teaching (ELT) plays in dealing with this problem. The main reason behind cheating, which seems to reflect the prevailing socio-cultural dimension, is highlighted and measures to address the attitude are put forward.
\end{abstract}

\section{Introduction}

Cheating is a serious concern in the academic world and that is why there has been a lot of research devoted to it (Firmin, Burger \& Blosser, 2007; Sasson, 2007; Dawkins, 2004). For instance, Schab (1991), in Firmin et al. (2007) in the research about high school cheating, reports that students using cheat sheets increased from $34 \%$ to $68 \%$, and students allowing others to copy rose from 58 to $98 \%$ over a period from 1969 to 1989 . Similarly, Jendreck (1992) in his research about students' reactions to academic dishonesty contends that less than $1 \%$ of students who observed cheating reported the incident to the instructor.

Cheating has been researched using qualitative and quantitative approaches by different researchers. For example, Firmin et al. (2007) conducted research among Psychology students with an aim of observing different stages that students go through when observing and reporting cheating. In their research they used individual, in-depth, qualitative 
interviews. On the other hand, Kirkvliet and Sigmund (1990) employed direct observation, the error overlap method, direct questions, and randomized response questions in their research where they explored the determinants of class-specific cheating behavior including students' characteristics and behavior and deterrent measures. Further, Jacob and Levitt (2003) used detailed administrative data when researching about the prevalence of teacher cheating. This research used observation via a video recording of a testing session with an aim of observing cheating behavior, and unstructured interviews in order to establish reasons why students cheat. But, although the research establishes occurrence of cheating and explains the attitude cheating students have towards it by way of highlighting the reason why students cheat, the underlying aim is to propose measures to address the attitude, hence the topic: English Language Teaching and the promotion of Academic Ethics.

\section{Defining cheating}

It must be noted that cheating has evolved to include a plethora of behaviours ranging from using crib sheets, digital devices like mobile phones, to copying from the next person, and so on. In fact, Dawkins (2004) lists different types of cheating including using crib notes, copying from others, helping others to cheat, inappropriate collaborations in assignments and high-tech cheating. Similarly, one College lists the following examples of cheating:

(i) Communicating during an examination with any person other than a properly authorized invigilator or another authorized member of staff;

(ii) Introducing any written or printed materials into the examination room unless expressly permitted by the Assessment Board or programme regulations;

(iii) Introducing any electronically stored information into the examination room unless expressly permitted by the Assessment Board or programme regulations;

(iv) Gaining access to any unauthorized material relating to an examination during or before the examination;

(v) Obtaining a copy of an 'unseen' written examination paper in advance of the date and time for its authorized release;

(vi) Falsifying data; and

(vii) Personating.

(Caledonian College of Engineering, 2006, pp. 40-41)

Interestingly, Jacob and Levitt (2003) explored cheating on the part of teachers and administrators, which they argued is linked to incentives for high test scores that may lure unscrupulous teachers to engage in a range of illicit activities including changing student responses on answer sheets, filling in the blanks when a student fails to complete a section, allowing students extra time to complete tests, providing correct answers to students, or 
obtaining copies of an exam illegitimately prior to the test date and teaching students using knowledge of the precise exam questions.

In fact, although cheating may not be considered a serious crime in the broader society (Visser, 1993, p. 60), Kerkvliet and Sigmund (1999, p. 332) report that many (Tittle \& Rowe, 1974; Michaels \& Miethe, 1989; and Mixon, 1996) see cheating in the same light as other criminal activities, which implies that a cheater, as a rational thinker, knowingly cheats, consciously aware of the wrongness.

Therefore, researchers in this field have highlighted inter alia measures for detecting, preventing and minimizing cheating. Firmin et al. (ibid), for example, conducted a research on peer reporting by looking at the cognitive processes that students experience when witnessing cheating. They (ibid) acknowledged that most of the published research on cheating has focused on describing the characteristics of students who cheat and the potential means of thwarting the behaviour. Thus, Firmin et al's (ibid) research was principally concerned with student's reactions when observing cheating. That is, how such observations influence reporting or not reporting.

Dawkins (2004), on the other hand, studied the attributes and statuses of college students associated with classroom cheating; whilst Kirkvliet and Sigmund (1999) considered the determinants of class-specific cheating behavior, including students' characteristics and behavior and deterrent measures. It is apparent that cheating takes different forms, more so at this era of digital revolution. However worse the situation progresses, it is still relevant to probe the reasons behind student cheating.

\section{Causes of cheating among students}

Kerkvliet and Sigmund (1999) hypothesized that an increase in the benefits associated with undetected cheating will encourage students to cheat; or conversely, an increase in the benefits of not cheating will decrease the probability of cheating; and while increases in the severity of penalties imposed on students who are detected cheating will increase cheating, measures that increase the probability of detection will discourage it.

On the one hand, Sasson (2007) concluded that students cheat because of many reasons, the main one being that they do not feel they can succeed on the test and as a result, they feel a 
need to cover up for whatever weaknesses they may have. Dawkins (op cit.), on the other hand, reported that more important in the decision to cheat are informal networking, and socialization among students. However, Niels (2009) propounds that students cheat by reason of survival instinct. He asserts that such instinct is linked to a fundamental mechanism within each one of us to 'save face', which may mean a desire to save oneself from the angry assault of parent or teacher; avoiding embarrassment; economic survival or a perceived pressure be it self-inflicted or inflicted by some other extraneous force. He (ibid) further argues that they might also cheat because they find a lesson or a course to be meaningless having no perceived relevance to their lives and because they believe something is unfair, thus they feel justified in cheating.

It appears that unlike Sasson (2007) who suggests covering of weaknesses being the reason behind cheating and Dawkins (2004) who refers to students' secret networks as propellers of cheating behavior; Niels's reasons for student cheating are seemingly biased in favour of students. His arguments do not place cheating on the evil end of the continuum, but somehow condones it as inevitable and necessary in particular instances of, say survival, just as one would scale a barbed wall escaping the jaws of a fearsome hound. Similarly, Kennedy (2009) in an in-depth interview with Niels, concludes that students cheat because they believe everybody does it; because of unrealistic demands for academic achievement by state education boards; and because of expediency or easy way out.

Nevertheless, Niels (op cit.) warns of dire negative implications and consequences of cheating, chief among which are the lowering of one's self esteem; deceiving people into believing that you know more than you do; violation of teacher's trust; being unfair to those who are not cheating; and increasing the likelihood of cheating in other situations later in life.

\section{Research}

As mentioned, this research was conducted in a College among Foundation students in a Reading testing session. As stated before, this research employed qualitative approach which attempted to present the data from the perspective of the subjects or observed groups so that the cultural and intellectual biases of the researcher would not distort the collection, interpretation, or presentation of data (see Jacob 1987 cited in Seliger and Shohamy 1990, p. 118). Furthermore, concern for the size of the subject population does not apply to qualitative research in which the objective of the research is heuristic; i.e., the size of the subject 
population could be as small as one subject depending on the research design, the topic, and even the type of data which are the focus of the study (see Seliger \& Shohamy 1990, p. 99). That is, this research does not seek to test any hypotheses, but rather to generate hypotheses from the findings and ipso facto renders the sample size of the population irrelevant. In fact, the research seeks to establish the occurrence of cheating by observing students in a testing session and thereafter find the reasons why cheating students cheat which is pivotal in proposing measures for thwarting the behavior. In other words, this research is not concerned about the number of cheating students, but the presence of cheating behavior and the attitude that cheating candidates have towards it so that corrective measures could be suggested.

A video camera was used to record the entire testing session with an aim of observing cases of cheating. It should be pointed out that the video was not only used as a data collection tool but also a deterrent measure, as students would naturally be wary of being caught in a video camera cheating. Prior to testing, a Reading lesson was conducted where students sat as they wished in a traditional rows format. Students were told at the start of the lesson that there would be assessment before the end of the lesson. Just before assessment commenced, students were re-seated so that there were spaces between each student (see Table 1). This was not only done so that students' proximity would render cases of cheating more obvious but also in consideration of Firmin et al's (op cit.) assertion that smaller class sizes and ample spaces between seating decrease cheating. Furthermore, students were warned that their papers were not going to be marked should they be caught cheating. This was in approximation of Seeman's (2004) advice that if you tell students before the test that if you suspect anyone is cheating, you will not say anything during the test - if they get their papers back with points off they will know why. The video was placed at the back of the class where the researcher spent most of the time as Seeman (op cit.) suggests that the teacher sits at the back of the room because when students cannot see him/her well, they are usually more nervous about trying to cheat. He (ibid) further argues that those who are tempted to cheat would try to turn around to see where the teacher is, which makes it easy to spot potential cheaters.

Table 1 shows the seating arrangement of the students. Each alphabet and number (e.g. A1, B1, C1, etc.) stands for a seat. 
Table 1: Seating arrangement

\begin{tabular}{|l|l|l|l|l|l|l|l|l|}
\hline A 1 & B 1 & C 1 & D 1 & E 1 & F 1 & G 1 & H 1 & I 1 \\
A 2 & B 2 & C 2 & D 2 & E 2 & F 2 & G 2 & H 2 & I 2 \\
A 3 & B 3 & C 3 & D 3 & E 3 & F 3 & G 3 & H 3 & I 3 \\
A 4 & B 4 & C 4 & D 4 & E 4 & F 4 & G 4 & H 4 & I 4 \\
\hline A 5 & B 5 & C 5 & D 5 & E 5 & F 5 & G 5 & H 5 & I 5 \\
\hline A 6 & B 6 & C 6 & D 6 & E 6 & F 6 & G 6 & H 6 & I 6 \\
\hline A 7 & B 7 & C 7 & D 7 & E 7 & F 7 & G 7 & H 7 & I 7 \\
\hline
\end{tabular}

Highlighted numbers represent occupied seats, for example A1, A2, A3 etc.; thus B1, B2, B3 etc., for instance, were not occupied. Whilst G2, D2 and B4 represent female students, C5 represents the video camera and C6 the teacher behind the camera. The class therefore had 22 students consisting of three females (B4, D2 and G2) and 19 males. There were two aisles: one between I1-7 and H1-7, and the other between B1-7 and C1-7. Table two below shows cheating patterns as captured in the video.

Table 2: Cheating patterns

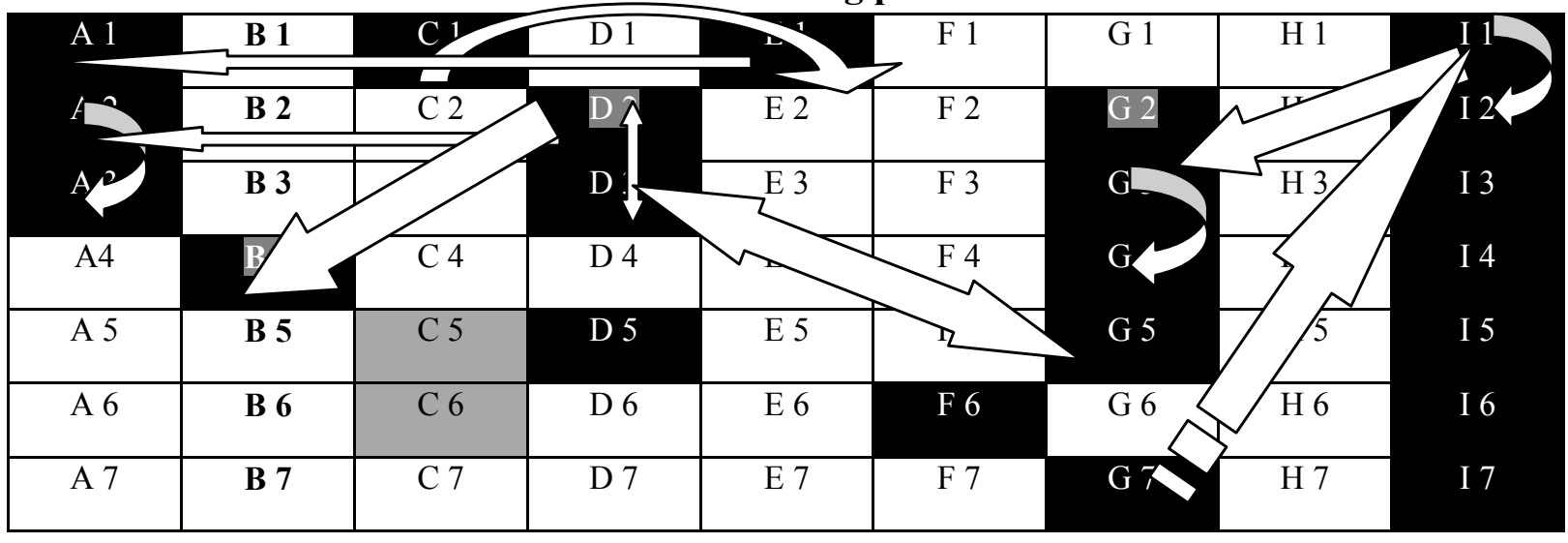

The direction of the arrows in Table 2 above indicates the point from which cheating started to the point of culmination. A double arrow shows that the two candidates were equally engaged in cheating. The arrow with a dotted tail indicates that the candidate moved from his place to the point indicated by the arrow.

That is, candidate E1 was spotted asking for answers from candidate A1. Similarly, candidate $\mathrm{C} 1$ asked for information from E1. In fact, candidates D3, G3, I1, and D2 asked for answers from D2, G4, I2, and A2, respectively. In addition, D3 asked for answers from G5. However, D2 was caught giving answers to B4 and D3 whilst G5 was giving answers to D3. In addition to asking I2 for answers, I1 asked G2 as well. A different case involved A2 who was caught copying from A3. Another different one was G7, who after finishing the test 
moved from his seat, five minutes before the end of the session, to I1, presumably to give him answers. Table 3 therefore, summarises aspects of cheating as discussed above.

Table 3: Aspects of cheating

\begin{tabular}{cccc}
\hline Asking for answers & Giving answers & Copying & Moving \\
\hline E 1 & D 2 & A 2 & G 7 \\
D 2 & G 5 & & \\
D 3 & & & \\
I 1 & & & \\
G 3 & & & \\
\hline
\end{tabular}

It is clear that most cheating cases involved students who were asking for answers as compared to those who were simply giving answers. Those who were being asked had an option of either giving answers or turning a blind eye. Obviously, there were those who chose to give answers like D2 and G5. Table 3 also shows that most students chose to ask rather than copy without permission; only one student did so. This indicates a level of collaboration among cheating candidates, implying that cheating in this case is largely communal as opposed to individual behaviour. Moreover, it is noticeable that most cheating cases involved talking either by asking or giving answers. This could be the result of the seating arrangement, as students would not easily copy from each other without being discovered, whereas they could talk out answers without putting their eyes on someone's answer script. However, just like the cheating detector picking up suspiciously similar responses from different candidates, a student being asked is equally at risk of cheating, especially when, like D2 and G5, he/she responds and thereby collaborates in wrongdoing. Therefore, a significant number of students in this study were found cheating.

Candidates that were caught cheating were asked, afterwards, to give reasons why they were cheating. Other students who were also caught cheating in other testing sessions were also asked to justify their behavior. Interestingly, all the respondents denied to have cheated, instead they said they were only helping (especially those who gave answers) or looking for help (i.e. those who either copied or asked for answers). It was noted that some students had generally asked for 'help' even from some invigilating teachers. In another different case, a parent turned up to petition for a student who did not make it in the final exams. This parent also asked for 'help' on behalf of the student. It therefore became important to consider the implication of 'help' being their only reason for cheating, the discussion of which follows below. 


\section{Help}

By definition given in Accurate and Reliable Dictionary (ARD), help means to furnish with strength or means for successful performance of any action or the attainment of any object; to assist; to aid. It also means to furnish one with means of deliverance from trouble; as, to help one from distress, say from prison. Conversely, failure to help means harming, blocking, counteracting, hindering, obstructing, and worsening one's situation. This means students who are asked for answers in the exam situation are likely to feel a moral obligation to 'help.' On the other hand, those who ask for answers may not feel that they have done anything wrong. This suggests that students in such occasions are unlikely to report cases of cheating as we have noted previously that less than $1 \%$ would do so. It could not be further from the truth that students who resist to 'help' may be regarded as obstructers or blockers of their fellows' progress, or even outcasts in a collaborative society where everyone is obliged to 'help.'

Another pressing concern is that which involves students asking 'help' from invigilators. Although it has not been established in this research that teachers succumb to this plea, elsewhere it has been noted that cases of cheating teachers are on the rise (Jacob \& Levitt, 2003). This obviously has a potential of legitimizing cheating under the guise of 'help' and may instigate hate or sabotage to those who refuse; thus increasing pressure among undiscerning teachers to engage in academic dishonesty.

Similarly, the tendency of certain parents to seek 'help' for their children is equally disturbing, especially in the current understanding of the term. Niels (2009) concluded in his discussion about why students cheat, that the reason they do so is because everybody does it. However, Niels (op cit.) puts the blame on the broader society, particularly parents, who he argues cheat about their taxes or lie about their age, thus setting a negative precedence for children. Therefore, parents may be labeled as collaborators or catalysts for this malpractice. As a result, these concerns raise questions about the attitude and the role of the broader society in promoting cheating and possible involvement in combating it.

\section{Discussion}

As it has been noted, cheating means different things to different people. Niels (ibid), for example, reports that in the past sociologists and psychologists studied cheating behavior under the classification of deviant or aberrant behaviour. Now, he argues, it is normal 
behavior, which he acknowledges it creates challenges for those seeking to establish academic integrity. The results in this research confirm that cheating no longer carries a stigma; it is regarded as a legitimate means of aiding oneself or someone else from a stressful or difficult situation. In fact, this is confirmed by the fact that most students who were caught cheating, in this study, were not involved in an individual behavior, but a communal or collaborative activity, which is dismissed simply as 'help'. This notion is seemingly spread out among students, possibly teachers and parents.

Arrizza (2009), arguing from a spiritual perspective on the true meaning of help, asserts that real help means an aid that will enable one to resolve one's life problems on one's own, which makes one feel stronger, happier, better about oneself, more resilient, capable, confident, energized, successful and fulfilled. Conversely, Arrizza (op cit.) contends that false help refers to a need for an outside party to resolve one's problems. He (ibid) concludes that this type of help leaves one feeling weak, needy, vulnerable, desperate, afraid, alone, inadequate, and poorly about oneself. This obviously shows that cheating has negative ramifications, whilst preparing oneself so much as to leave no room for cheating has positive results.

Clearly, the help that students and parents seek as a short cut to immediate challenges does not help in the long run. In fact, as Arrizza (op cit.) implies, it creates a vicious cycle where the one who seeks for help develops dependence upon that; that is, the cheater relies more and more on cheating until it assumes second nature. This is confirmed by a significant number of cheating students in this study.

Furthermore, as mentioned previously, data indicates that cheating behavior shifts from just being an individual endeavor to being a collaborative effort. There seems to be communal agreement among students to assist one another. This is evidenced by a number of students asking for help and receiving help from others. Of greater concern is the attitude that cheaters have towards it. They are apparently naïve or ignorant of the expectations of academic ethics and the severity of penalties that go with cheating. It is this attitude that may bring into play even hard to detect cheating behaviours. As noted, most cheating behaviours had to do with talking. This cheating behaviour becomes difficult to deal with especially when evidence needs to be provided to prove the one that benefited from cheating. Whilst it is possible that such talking may not have benefited anyone, it is equally true that some or many may have; 
unfortunately some of this talking may go unverified as the student may use the language inaccessible to the invigilator. Nevertheless, the matter may not have to be whether anyone benefited or not, but that behaviour disallowed in the exam environment was detected.

It must be noted that stringent measures are almost always taken against those who are caught cheating in an attempt to send a strong message to deter the mal-behavior. Most decisions taken against the guilty are based on evidence brought before any disciplining body and largely take into consideration the unfair benefits enjoyed by the cheater in an exam. However, as this research suggests, rules and regulations, though they need strict enforcement as a deterring mechanism, are not adequate in addressing the attitude that students and the larger society have towards cheating. Attitude is seen as a motivating factor for students to cheat, which, if it goes unchecked, may develop into a quasi-acceptable behavior to the detriment of academic ethics. This may not be in the remote future as it has been presented that cheating is no longer regarded as deviant behaviour as it was in the past. Therefore, researchers in this field such as Niels (2009) strongly contend that control of academic dishonesty will not be accomplished by threat of punishment alone; the most effective deterrent will be a commitment to academic integrity within the student peer group. This means, students need involvement, which could be through being part of academic ethics promotion or any other initiative aimed at cultivating academic integrity. The crux is to change students' attitude towards cheating so that they see it as malpractice tantamount to criminal behavior in academic circles. It has also been suggested in this study that whilst parents need to model integrity, academic institutions may have to enlighten them on academic ethics, especially when it seems to conflict with general behavior in the society, in this context the meaning of 'help' and how it could be positively translated in an academic environment. Furthermore, it would benefit academic institutions to consistently inform and update teachers about academic integrity. In a more practical way we shall consider how English Language Teaching could help in the fight against academic dishonesty the discussion of which follows below.

\section{ELT and promotion of academic ethics}

In the light of Niels' (op cit.) argument that students need to play an active role in fostering academic integrity, Scrivener (2005) postulated that "the subject matter of English can encompass all topics and purposes that we use language to deal with" (p. 33), perhaps including topics in the area of academic ethics as demonstrated below. Academic Ethics 
could be covered in a range of classroom activities including research projects, role plays, and text exhibitions to mention a few. Hassim and Fahmi (2007) put together a range of activities that could be adapted for purposes of addressing issues in academic ethics. The two activities outlined below are an example of the many possible ones that could be covered in an English Language classroom:

(a) Poster exhibition

Learning outcomes:

(i) Students would be able to demonstrate knowledge of rules and regulations relating to academic integrity in their institution.

(ii) Students would be able to gauge their understanding of academic integrity against that of their teachers.

(iii) Students would be able to advise fellow students on issues relating to academic integrity.

Remit:

Write a poster for new students advising them about how they are expected to carry themselves in as far as academic integrity is concerned.

Procedure:

Students would work together in groups of say five. First, they should share and record ideas they have about say cheating, i.e., meaning, reasons, penalties etc. Second, they interview at least five members of staff (preferably their teachers) so they can get ideas on the meaning, reasons and penalties for cheating students. Next step consists of surveying institution's documents on the subject of cheating. Finally, they will have to write a poster for new students advising them about how they are expected to carry themselves in as far as academic integrity is concerned.

\section{(b) Role Play}

Learning outcome:

Students would be able to critically judge cases of academic misconduct.

Remit:

Write a script for the performance of the following situation: The institution's disciplinary board is in session to deliberate on the case involving a student who was caught cheating. In 
attendance is the guilty student, the teacher who caught the student, and the parent of a student. The chairperson of the proceedings is the principal of the institution. Your script should address these areas: (i) Reasons for cheating; (ii) Impact of cheating in the institution; (iii) Impact of cheating on a student; (iv) Impact of cheating on the community; and (v) Any area of your choice that will help combat cheating.

Procedure:

1. Students organize themselves into groups of say minimum five per group. Such a grouping should take into account the roles that must be covered, i.e. there should be a principal, a student, a teacher and a parent, but of course the board would have other members playing ancillary roles.

2. Students deliberate the proceedings of the session assigning utterances to the board members. They should cover the whole interaction from the start of the session to the end. The teacher should be available to assist them with any questions they may have.

3. Students decide among themselves characters who would act out the proceedings of the meeting. When doing so they should take into account their personalities so that characters resemble real life persons.

4. Students evaluate each group's rendition and vote for the best performance

5. This activity could be extended into an institution's wide activity to be performed say as part of orientation programmes for new students or in any institution's special occasions.

\section{Conclusion and recommendations}

Evidence of cheating and reasons presented by cheating students in this research are testament to the deteriorating attitude towards this scourge and a threat in the academic society. Cheating is seemingly not regarded as nefarious as it should be; it has been elevated to a point where it seems as normal as copying lecture notes from a board. There is a need to address the institutions' stakeholders, i.e. parents and the entire community inclusive of teachers and students on the subject. It would further benefit both students and the academic community to include a course in academic ethics, which would cultivate a behavioral culture that promotes academic integrity. This would make penalties that are a deterrent to cheating not only more meaningful, but reflective of the values of the academic environment. Most importantly, the attitude of students and other stakeholders towards cheating would have to be 
addressed hoping to turn it around. In the light of this, the following recommendations are made:

- Deterrent measures to curb cheating need to be consistently employed;

- A course in academic ethics needs to be developed and offered in academic institutions preferably embedded in English Language course;

- Academic institutions should consider enlightening the broader society on the meaning of academic integrity and ethics;

- Teachers should be consistently apprised about the values of academia and the promotion of academic honesty.

\section{References}

Accurate and Reliable Dictionary. (2009). Retrieved from http://ardictionary.com/Help/2228

Arrizza, N. (2009). Spirituality: The True Meaning of Help. Retrieved June 29, 2009 from http://EzineArticles.com/?expert=Nick_Arrizza,_M.D.

Caledonian College of Engineering. (2006). University Regulations Regarding Plagiarism and Cheating. Retrieved from http://intranet.cce.edu.om/TimeTable/GCU\%20Plagiarsm\%20Regualtions.pdf

Dawkins, R.L. (2004) Attributes and Statuses of College Students Associated with Classroom Cheating on a Small-Sized Campus. College Student Journal. 38. Retrieved July 4, 2009 from http://www.questia.com/googleScholar.qst;jsessionid=K91Mf9vZT1t1lLntMhkpqdB5v1QtKwSgTp4Nr ygSbzxy1 WPrPPF6!2080363699!-1402025386?docId=5006016963

Firmin, M.W., Burger, A. \& Blosser, M. (2007). Cognitive responses of students who witness classroom cheating. Journal of Instructional Psychology. Retrieved from http://findarticles.com/p/articles/mi_m0FCG/is_2_34/ai_n27296410/

Hassim, M. \& Fahmi, E. (2007). Newsletter of the Moroccan Association of Teachers of English (MATE). 28(1-2) Summer - Autumn 2007 (online) Retrieved from http://www.mate.org.ma/NLSup9CivEdu.pdf.

Jacob, B.A. \& Levitt, S.D. (2003). Rotten Apples: An investigation of the prevalence and predictors of teacher cheating. Quarterly Journal of Economics. 118, 843-78

Jendrek, M. P. (1992). Students' reactions to academic dishonesty. Journal of College Student Development, 30, 260-273.

Kennedy, R. (2009). Gary Niels on cheating. Retrieved from http://privateschool.about.com/cs/forteachers/a/cheating_4.htm

Kerkvliet, J. \& Sigmund, C. L. (1999). Can we control cheating in the classroom? Journal of Economic Education. 30, 331-43.

Michaels, J., and T. Miethe. (1989). Applying theories of deviance to academic cheating. Social Science Quarterly, 70, 870-85.

Mixon, F. 1996. Crime in the classroom. Journal of Economic Education 27 195-200.

Niels, G. (2009). 5 ways to prevent cheating. Retrieved from http://privateschool.about.com/cs/forteachers/a/cheating 4.htm

Sasson, D. (2007). Cheating in the classroom. Retrieved from http://newteachersupport.suite101.com/article.cfm/cheating_in the classroom\#ixzz0J2KHzeEj\&D

Schab, F. (1991). Schooling without learning: Thirty years of cheating in high school. Adolescence, 26, 839-847.

Scrivener, J. (2005). Learning teaching. Oxford: Macmillan

Seliger, H.W., \& Shohamy, E. (1990). Second language research methods. Oxford: Oxford University Press.

Seeman, H. (2004). Cheating: Tips and advice for preventing and handling. Retrieved from http://www.educationworld.com/a_curr/profdev/profdev045.shtml

Tittle, C., \& A. Rowe. (1974). Fear and the student cheater. Change 6 (3), 47-48.

Visser, N. (1993). Handbook for writers of essays \& theses. Cape Town: Maskew Miller Longman. 